\title{
Hydraulic Turbine Performance Assessment with Implementation of an Innovative Aeration System
}

\author{
Florentina Bunea ${ }^{1}\left(\mathbb{D}\right.$, Gabriel Dan Ciocan ${ }^{2}$, Diana Maria Bucur ${ }^{3, *}{ }^{(\mathbb{D}}$, Georgiana Dunca $^{3, *}$ and Adrian Nedelcu ${ }^{1}$ \\ 1 Department of Renewable Energy Sources and Energy Efficiency, \\ National Institute for R\&D in Electric Engineering ICPE-CA, 030138 Bucharest, Romania; \\ florentina.bunea@icpe-ca.ro (F.B.); adrian.nedelcu@icpe-ca.ro (A.N.) \\ 2 Laboratoire de Machines Hydrauliques, Université Laval, Québec, QC G1V 0A6, Canada; \\ gabrieldan.ciocan@orange.fr \\ 3 Department of Hydraulics, Hydraulic Machinery and Environment Engineering, \\ Faculty of Energy Engineering, University Politehnica of Bucharest, 060042 Bucharest, Romania \\ * Correspondence: diana.bucur@upb.ro (D.M.B.); georgiana.dunca@upb.ro (G.D.)
}

check for updates

Citation: Bunea, F.; Ciocan, G.D.; Bucur, D.M.; Dunca, G.; Nedelcu, A. Hydraulic Turbine Performance Assessment with Implementation of an Innovative Aeration System. Water 2021, 13, 2459. https://doi.org/ $10.3390 / w 13182459$

Academic Editors: Inmaculada Pulido-Calvo, Mark S. Bevelhimer and Brenda M. Pracheil

Received: 12 July 2021

Accepted: 1 September 2021

Published: 7 September 2021

Publisher's Note: MDPI stays neutral with regard to jurisdictional claims in published maps and institutional affiliations.

Copyright: (c) 2021 by the authors. Licensee MDPI, Basel, Switzerland This article is an open access article distributed under the terms and conditions of the Creative Commons Attribution (CC BY) license (https:// creativecommons.org/licenses/by/ $4.0 /)$

\begin{abstract}
The environmentally friendly concept in terms of water quality represents a condition for developing hydropower plants all around the world. Since 2017, hydropower has represented more than $70 \%$ of all renewable energy production and it is essential for the integration of the other renewable sources of energy and for regulation of the grid. To maintain the "green" label concerning the dissolved oxygen level $(6 \mathrm{mg} \mathrm{DO} / \mathrm{L})$, the energy suppliers should respond to environmental concerns about the operation of hydropower plants. In the context of sustainable development, the ecological degradation of rivers is unacceptable due to the implementation of a hydropower plant on the watercourse. For deep reservoirs or tropical regions, the oxygen level in the water downstream of the hydropower plants may be low and affect the aquatic life for many kilometers downstream. This paper presents a new aeration system for discharged water from hydropower plants that provides water aeration with minimum energy consumption. The influence of the aeration process on the turbine operation and efficiency is analyzed. Experimental measurements are carried out on site on a small Francis turbine. The influence of the aeration process on the turbine mechanical performances (vibration level and relative displacement) and hydraulic performances (turbine efficiency, power output, and pressure fluctuation) is analyzed. The results showed that the impact of the aeration device implementation and operation over the energetic characteristics of the turbine is in the efficiency measurements accuracy range. The aeration through this device did not influence the turbine operation (vibration, level, or pressure fluctuations).
\end{abstract}

Keywords: water aeration; environmentally friendly turbines; Francis turbine efficiency

\section{Introduction}

The main objective of the European Water Policy is to achieve a "good state" for all ground and underground waters in all EU countries and associated areas and also to achieve the "good ecological potential" for essentially modified and artificial waters. The environmentally friendly concept is a worldwide concern related to the protection of water resources and is part of environmental policies [1].

The environmentally friendly concept is a condition for the development of hydro projects in all countries. In the context of sustainable development, the ecological degradation of rivers caused by the implementation of a hydropower plant (HPP) on the watercourse is not acceptable. The most critical situations are in the case of high dams, where the water intake for the hydraulic turbines is in the bottom layers of the reservoir, where the dissolved oxygen (DO) level is minimal due to the high pressure, organic matter content, and nutrients concentration [2]. Moreover, when the water passes through the hydraulic turbine, the DO level continues to decrease due to the decreasing pressure and, at the 
turbine outlet, the $\mathrm{DO}$ level can be lower than the minimum value required for the aquatic life (approximately 4-6 mg/L [3]).

In the United States, the high interest in solving water quality problems led to the development of the Water Quality Analysis Simulation Program (WASP) [4], which has been continuously improved since 1970 by the US Environmental Protection Agency. A low DO content in rivers is considered a pollution factor. There are situations when the DO level drops down to $0-2 \mathrm{mg} / \mathrm{L}$ [5]. The DO level depends on several parameters: the temperature and/or the climate of the area where hydropower plants are located, the level of organic substances in reservoirs [6,7], the depth of the water intake of the turbine (especially when the intake is placed in the deep layers of the reservoirs, where the DO level is the lowest), the type and operating regimes of the HPP, and the pressure level in the draft tube of the turbine (especially for Francis turbines when operating in partial load). A low DO level occurs when the following conditions are met: the reservoir has a depth greater than $15 \mathrm{~m}$, the reservoir volume is larger than $61 \cdot 10^{6} \mathrm{~m}^{3}$, the power output is more than $10 \mathrm{MW}$, and the retention time of water in the reservoir is longer than 10 days [8-11].

As an example, in tropical countries such as Malaysia, Bakun dam [5], 88\% of the storage reservoirs have a zero DO level in the layers deeper than $4 \mathrm{~m}$, and the river water quality is affected for $3-5 \mathrm{~km}$ downstream of the HPPs. Another example of the water quality monitoring of Hongqi River, China [12], showed an increased concentration of phosphorus and nitrogen and a low DO level in water downstream of the HPP [13].

In order to avoid the negative effect of a low DO level on the environment, the development of aeration systems is essential in such locations.

Usually, the aeration is realized using existing equipment in hydropower plants (selective water intakes, sluices, weirs, and surface pumps) or through the anti-cavitation systems of the hydraulic turbines. For these conventional aeration methods, the aeration efficiency is limited because they are designed only for optimal hydraulic performances, not adapted for aeration process.

Considering the importance of the DO level in water, the suppliers implement conventional methods of air injection for the impacted power plants. For these conventional methods of aeration, the process is not always successful.

Starting from 1950, the main energy suppliers and hydro equipment manufacturers from Europe and the USA have been involved in the environmental aspects of the HPP operation. In the USA, at Bull Shoals, which is equipped with Francis turbines, deflectors mounted on the runner were used for water aeration since 1991 [14]. The deflectors were placed in such a way to create a maximum under pressure level for air admission, aiming to maintain the downstream DO at a minimum of $4 \mathrm{mg} / \mathrm{L}$.

Other researchers $[15,16]$ tested several alternatives for the injection of air through a runner or a redesigned deflector, turbine blade trailing edges, coaxial diffuser, discharge ring, draft tube, or combinations of them. Their purpose was to aerate the water downstream, with a minimum effect on the energy production efficiency and HPP power output.

The Tennessee Valley Authority proposed a modernization program to address the HPP downstream DO level issue in the frame of turbine refurbishment [17]. Self-ventilating turbines were implemented for the first time at Norris Dam and used the three main types of aeration: central aeration, distributed, and peripheral. To evaluate the environmental effect and energy performance, measurements were carried out using these aeration techniques. Each option (in simple operation or combined with the others) was tested on a wide range of turbine operating regimes. For a single turbine, the DO increased up to $5.5 \mathrm{mg} / \mathrm{L}$ by operating all aeration systems. Depending on the operating conditions and the aeration option, the energy production efficiency decreased by $0 \div 4 \%$. The auto venting turbine (AVT) is a self-aspirating hydro-turbine designed to aerate the turbine discharge through ports located at low-pressure regions, which are connected to the atmosphere. The important factors influencing the performance of an AVT were highlighted: the quantity of entrained air, the air/water interfacial area, i.e., the bubble size [18] For the AVT system, 
the bubble size is not controlled because the air is introduced by baffles, and in this way, the oxygen transfer rate, dependent of the interfacial area, is not controlled.

The efficiency of AVT was analyzed and compared in the literature [19], discussing the influence of the main aeration parameters: turbine geometry, the amount of air, and the location of air injection [20]. Nevertheless, although the size and the distribution of air bubbles are mentioned, they are not particularly considered or investigated in neither of these studies, even though they are one of the main factors in the oxygen transfer process. Each aeration method has different characteristics and influences the size and distribution of bubbles flowing through the turbine draft tube at different operating regimes [21].

Another aerating solution is the Updraft Free Exit turbine, a sort of Francis turbine, which allows the water to flow upward and exit at the free surface near the tail water elevation. As the flush plunges into the tailrace, it improves the natural aeration process, air entrainment, and turbulent mixing, increasing the dissolved oxygen. Nevertheless, due to the low efficiencies, this type of turbine has not been further developed [22].

Studies and research also include mathematical modeling of flow [23,24]. Numerical simulation of two-phase bubbly flow in the wake of NACA0015 hydrofoil is carried out under different conditions [25]. A series of air injection experiments were conducted on a hydrofoil in several hydrodynamic conditions. In [26], the effects on the DO transfer of different generated bubble sizes are investigated. A one-dimensional mass transfer model is developed to lend insight into the mass transfer characteristics observed in these experiments.

The most-known systems for the aeration of discharged water are invasive, and even when they are not used, their presence may lead to a change of flow structure and thus to efficiency decrease (1-5\%) of the turbines [21]. In [25], different types of aeration devices are analyzed. The first was the conventional aeration by the center of the runner cone. To this base system, aeration enhanced by baffles or by a step in the runner cone was also tested. The third air admission tested method was the discharge ring. The fourth, aeration by the trailing edge of the wicket gates, was analyzed. Although this last system can produce well-distributed fine air bubbles, it usually requires a compressor injecting air at a pressure higher than atmospheric pressure.

Nevertheless, recently, non-intrusive aeration techniques were developed, but their implementation in existing turbines involves major changes of the existing design, and they can only be implemented in new machines or in those subjected to major rehabilitation. Additionally, the high energy consumption $[27,28]$ required for the introduction of air into the water hydraulic circuit is an aspect that has to be considered.

Despite the continuous development of aeration methods since 1950, the aeration devices for improving the quality of water downstream of hydro power plants are still not in place in most of the existing hydropower sites where it is needed, even if a few scales up, installations were developed in time. The method of aeration of water passing through hydraulic turbines has to be evaluated for each specific case. As for efficient power generation, each hydraulic turbine is designed according to the site characteristics and so are the aeration devices that are envisaged to equip the hydraulic circuit [18].

In the present work, an innovative non-intrusive aeration device is developed and tested. The aim of the device is to aerate the water during the transit through the hydraulic turbines. The innovative character of this aeration device reflects in the following aspects: the dispersion of the air is performed with an optimal gas-liquid contact area compared to the energy needed for injection [29]; the location of the air injection is optimized compared to the draft tube flow behavior to ensure a longer retention time of the bubbles in water (increasing of the DO transfer time); the design of the device allows an easy and fast installation and maintenance. The main difference between the present device and the existing ones relies on its ability to create a non-invasive and disperse aeration with low energy consumption.

The innovative aeration device was implemented and tested on-site on a small Francis turbine. During the tests, both forced and natural air admission techniques were used. 
The investigation focused on the influence of the aeration process over the mechanical behavior and efficiency during the operation of the turbine. The following parameters were monitored: water levels upstream and downstream of the turbine, the pressure at the turbine inlet, the level at which the pressure transducer that measures the pressure at the turbine inlet is mounted, the flow rate, and the hydro-generator power output.

The non-influence character of the turbine efficiency of the present device is firstly assured by the design that replicates the internal geometry of the draft tube: the interior wall of the aeration system is identical to the original turbine draft tube, with small orifices that allow the air injection. Second, the air is introduced in the flow in small air bubbles that in a short time are mixed with the flowing water and spread in the entire draft tube, becoming a homogeneous mixture. The experimental tests, performed according to [8], without and with the aeration device operating, showed that the efficiency varied within the efficiency measurements accuracy range of $( \pm 1.5 \%)$, leading to the conclusion that the aeration through this device does not affect the turbine operation (vibration level, pressure fluctuations, and efficiency).

\section{Parameters Considered for Aeration Efficiency Balance}

Two main objectives have to be achieved by an aeration system: to increase the DO concentration in water with minimum energy consumption for air injection and not to affect the turbines' energetic performances.

For the implementation of the aeration device in the turbine the following constructive criteria have to be considered: accessibility for the implementation (to minimize the outage time and reduce the impacted turbine components) and facility for maintenance (standalone system does not impact the power plant availability).

In the current practice, the aeration in hydraulic turbines is evaluated by the total amount of injected air in water, expressed by the void fraction (Equation (1)).

$$
\varphi=\frac{Q_{\text {air }}}{Q_{\text {water }}} \cdot 100
$$

where $Q_{a i r}$ and $Q_{\text {water }}$ are the air and water flow rate, respectively. This is a global parameter, easy to evaluate but not relevant for the rate of DO transfer or the efficiency of the aeration.

However, for aeration purposes, to maximize the DO transfer level, the main parameter is the area of interphase contact air-water as large as possible, achievable by the dispersion of air in bubbles as fine as possible. In the study of two-phase gas-liquid systems, the hydrodynamic elements refer to the bubble generation regime [23], the variation of gas bubbles radius [30], the distribution of gas bubbles size [23], the fraction of global and local void fraction [29,31], and the coalescence and the bursting of bubbles [30]. Another major factor for the aeration efficiency is the transit time of the bubbles in the hydraulic circuit. The increase in the transit time allows more time for DO transfer, and, in this way, the increase in the transfer rate. Additionally, the main parameters of the flow through the hydraulic turbine must be taken into account for maximization of the oxygen transfer: the water flow velocity, the adverse pressure gradient in the draft tube, and the high turbulence level but also the air contact time until the water exit [29].

In order to limit the decrease in the energy efficiency, the fraction of injected air must not exceed $3 \% \div 5 \%(\phi<3 \% \div 5 \%)$ of the water flow rate of the turbine $[18,19]$. This limitation is empirical based on the flow behavior: for an air flow rate superior to $5 \%$, the flow behavior is modified, and the hydraulic efficiency decreases. Moreover, a higher fraction of air assumes the increase in the energy consumption needed to inject the air. The limitation of the amount of air introduced means that it will not always be sufficient using classical aeration systems in order to achieve the desired DO level, especially when the initial DO content in the water is less than $(2-3) \mathrm{mg} / \mathrm{L}$. This is a sensitive issue for manufacturers and operators of hydraulic turbines since injecting an extra amount of air into the turbine circuit can reduce its efficiency. Therefore, air injection (aeration type, 
location of air introduction, and air quantity) becomes important for the balance between turbine efficiency and environmental factor.

\section{Aeration System Implementation Study}

\subsection{New Aeration System}

The technical solution presented in this paper consists of the development of a water aeration system in hydraulic turbines to increase the dissolved oxygen DO level of the water flowing through the hydraulic turbines.

The main difference between the presented aeration system and the anti-cavitation systems is the introduction of air in fine disperse bubbles from the outside to the center of the draft tube, flowing in a mixture with the water, while the common anti-cavitation systems introduce the air through the runner hub, in a compact jet, forming large bubbles in the center on the draft tube.

Following the previous research [8], the oxygenation capacity of similar devices was measured on an experimental setup designed to simulate the turbulent flow at the entrance of a hydraulic turbine draft tube. The aeration efficiency of the air injection devices was characterized experimentally for different mean velocities of water upstream of the draft tube $(2.5 \mathrm{~m} / \mathrm{s}-9 \mathrm{~m} / \mathrm{s})$ and void fractions $(\phi=0.45-1.5 \%)$. Following this study, the aeration device was optimized (obtaining the best design for the maximum aeration with minimum energy consumption for air injection).

For the new aeration system, the air injection can be natural, requiring no energy consumption (based on the pressure difference between the atmospheric pressure and the pressure level in the turbine) or forced, using compressed air. Considering this aspect, the optimum location of the air injection is determined based on numerical simulation of the flow inside the hydraulic turbine, targeting the lower pressure level inside the turbine (to facilitate the air admission in flow with low energy consumption for admission). The numerical results of the flow in the prototype turbine indicate that the optimal location for air injection in turbine is downstream the turbine runner at the entrance of the draft tube.

In order to evaluate the aeration efficiency and the influence of this innovative aeration device over the operation of the turbine, it was implemented on a small horizontal Francis turbine. The turbine has the following rated parameters: power output, $P_{0}=318 \mathrm{~kW}$, head, $H_{0}=18 \mathrm{~m}$, and flow rate $Q_{0}=2 \mathrm{~m}^{3} / \mathrm{s}$. The turbine rotational speed is $375 \mathrm{rot} / \mathrm{min}$ with a specific speed of 210, determined according to Equation (2) [32].

$$
n_{s}=\frac{n}{H} \sqrt{\frac{P_{h p}}{\sqrt{H}}}
$$

The experimental analysis, performed on-site during the normal operation of the turbine, is focused on determining the turbine operating parameters evolution during the turbine operation across the entire load domain for different values of injected air flow rate. In order to evaluate the influence of the air injection over the flow structure at the runner outlet, the pressure in the elbow of the draft tube is monitored, and an optical borescope is used for bubble flow visualization. The main objective was to assess the influence of the aeration process during the turbine operation (efficiency, vibration, stability, and cavitation).

Considering the above aeration parameters and hydraulic turbine operation characteristics, a non-invasive aeration device is designed, manufactured, and tested on a real-scale small hydraulic turbine. The final design was developed starting from the studies over the aeration performances of different disperse aeration devices mounted non-invasively on the wall of a pipeline in a complex turbulent flow with cavitational vortex [31]. The aeration devices are tested for different void fractions in order to obtain the oxygen transfer efficiency for air injection. Based on this study, an aeration device equipped with perforated plates was developed. The plates have $0.8 \mathrm{~mm}$ orifices dispersed equidistantly with a step of five diameters in order to avoid the bubbles' coalescence. 
Starting from the results of this study that give the best aeration characteristics in similar flow conditions as in turbine flow, an aeration device to be implemented in hydraulic turbines was developed.

For the implementation of the aeration device in turbines, many criteria were considered: accessibility for the implementation (to minimize the outage time and reduce the impacted turbine components), the morphology of the flow to increase the dispersion of the injected air, the pressure level in the flow in order to reduce the energy consumption for the aeration, and the accessibility for control and maintenance. To satisfy these criteria, the draft tube cone was considered the best place for the aeration implementation because in most of the power plants it is accessible. Additionally, it is a part of the turbine that can be easily replaced in maintenance or refurbishment periods.

In order to implement this aeration device in other $n_{s}$ turbines, specific design and manufacture operations have to be processed. The air flow will be established starting from the water turbine discharge to the maximum value of $3-5 \%$ of the water discharge. Depending on the site arrangement (new turbine or refurbished), especially on the access zone to the turbine draft tube, the length of perforated wall of the draft tube, the orifice size, and distribution have to be determined. Once the injection orifices and distribution are defined, the mechanical design of the aeration device can be customized for the turbine.

\subsection{Numerical Study}

To test the flow behavior-very complex in this turbine part [33] — a numerical simulation, for the real operating conditions, was performed. The maximum depression areas were pointed out using numerical simulations in the draft tube, and the flow behavior was analyzed. The results of the numerical simulations were used to identify the optimum location of the disperse aeration device.

For the numerical tests, a large operating range of the turbine was considered. Three net heads, $H$, were chosen from the minimum to the maximum level available in the upstream reservoir and several flow rate values, $Q$, ranging from $50 \%$ to $110 \%$ of the rated flow rate. The turbine efficiency, $\eta_{T}$, was determined from the hill chart of the turbine (Figure 1) and presented related to the rated (maximum) efficiency. The energetic parameters of the analyzed regimes are presented in Table 1.

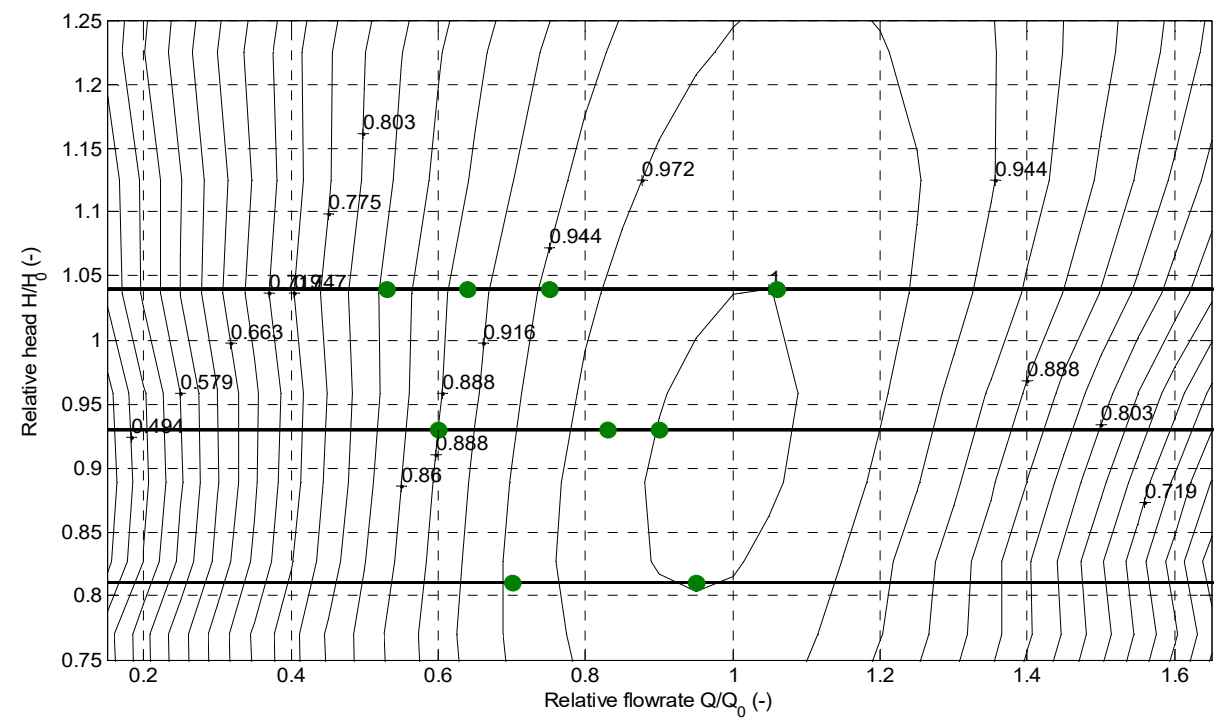

Figure 1. Efficiency chart of the turbine and operation regimes investigated in the numerical analysis. 
Table 1. The turbine operation parameters without aeration system used in numerical analysis.

\begin{tabular}{cccc}
\hline No. & $\begin{array}{c}H / H_{\mathbf{0}} \\
(\mathbf{m})\end{array}$ & $\begin{array}{c}Q / Q_{0} \\
\left(\mathbf{m}^{\mathbf{3}} / \mathbf{s}\right)\end{array}$ & $\begin{array}{c}\eta_{T} / \eta_{\mathbf{0}} \\
\mathbf{( \% )}\end{array}$ \\
\hline 1 & & 1.06 & 1.00 \\
2 & \multirow{2}{*}{1.04} & 0.75 & 0.95 \\
3 & & 0.64 & 0.90 \\
4 & & 0.53 & 0.83 \\
\hline 5 & & 0.90 & 1.00 \\
6 & 0.93 & 0.83 & 0.99 \\
7 & & 0.60 & 0.89 \\
\hline 8 & \multirow{2}{*}{0.81} & 0.95 & 1.00 \\
9 & & 0.70 & 0.94 \\
\hline
\end{tabular}

The numerical simulations were carried out for nine operation regimes (Table 1) using Ansys-CFX v.16.2 (Ansys, Canonsburg, PA, USA), considering the 3D geometry of the turbine draft tube. The unstructured mesh is created in Ansys-ICEM v.16.2 (Ansys, Canonsburg, PA, USA). In order to determine the optimum number of mesh cells, a sensitivity analysis was carried out. Three meshes having different cell numbers, $\mathrm{N}$, were tested: 923,520, 461,500, and 230,181. The mean pressure at the entrance of the draft tube was extracted for each mesh. It was observed that for meshes with a number of cells equal to or higher than $N=461,500$, the mean pressure at the entrance of the draft tube has an asymptotic variation. Thus, the mesh with $N=461,500$ cells was chosen. The boundary conditions at the entrance of the computational domain were set as the velocity components determined for the values of the flow rate in Table 1. At the outlet boundary, the relative pressure was set: 0,5621 , and $14,479 \mathrm{~Pa}$, corresponding to the three regimes available during in site operation. The simulations considered a steady-state regime of the flow and used the standard $\mathrm{k}-\varepsilon$ turbulence model.

The exact location of the lowest pressure region was identified, as expected, downstream of the turbine runner, at the entrance of the draft tube, so the aeration device was set in the draft tube cone (Figures 2-4). The limits for the pressure variation domain depended on the operation parameters, but the structure of the pressure field and velocity distribution was similar. Figure 2 presents the pressure variation domain in the entire draft tube (DT) for a flow rate of $0.9 Q_{0}$. It can be observed that in the draft tube cone section (CS), the pressure distribution has the lowest values, which was useful in establishing the location of the aeration device (Figure 3).
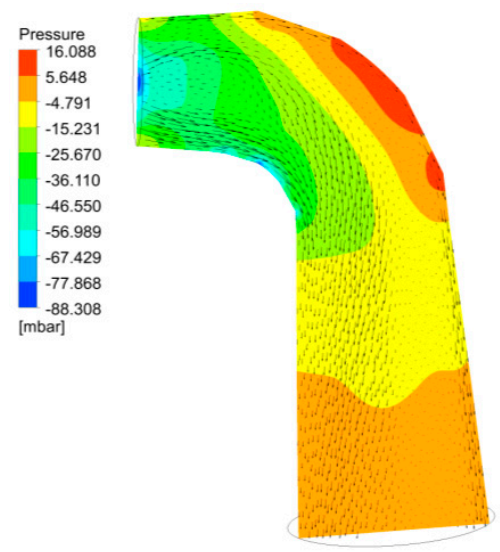

(a)

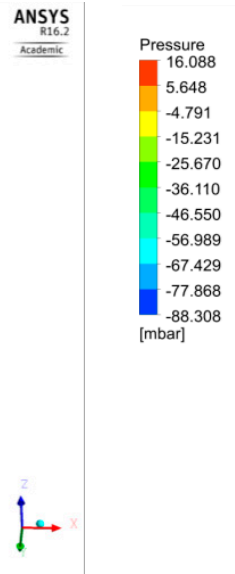

16.088
5.648
-4.791
-15.231
-25.670
-36.110
-46.550
-56.989
-67.429
-77.868
-88.308

670

110

.989

.868

(1)

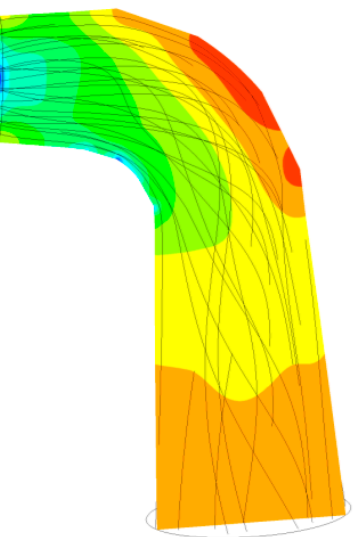

$\underset{\substack{\text { RY6.2 } \\ \text { Aectenic }}}{\text { ANSYS }}$

(b)

Figure 2. Pressure distribution, velocity vectors (a), and streamlines (b) in the analyzed domain for flow rate of $0.9 \mathrm{Q}_{0}$ and outlet pressure of $5621 \mathrm{~Pa}$. 


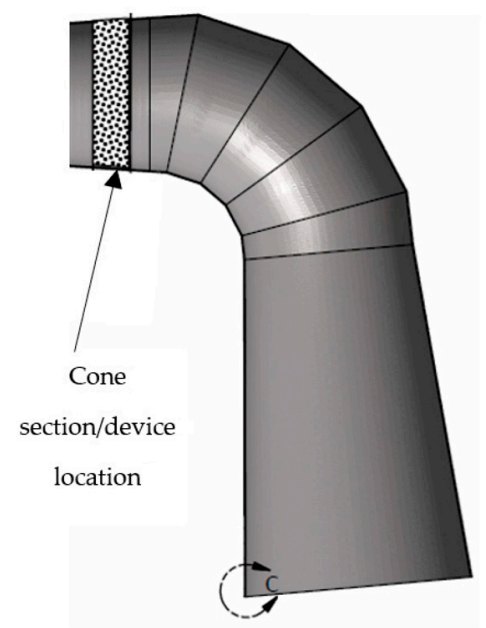

Figure 3. Recommended area for aeration device location.

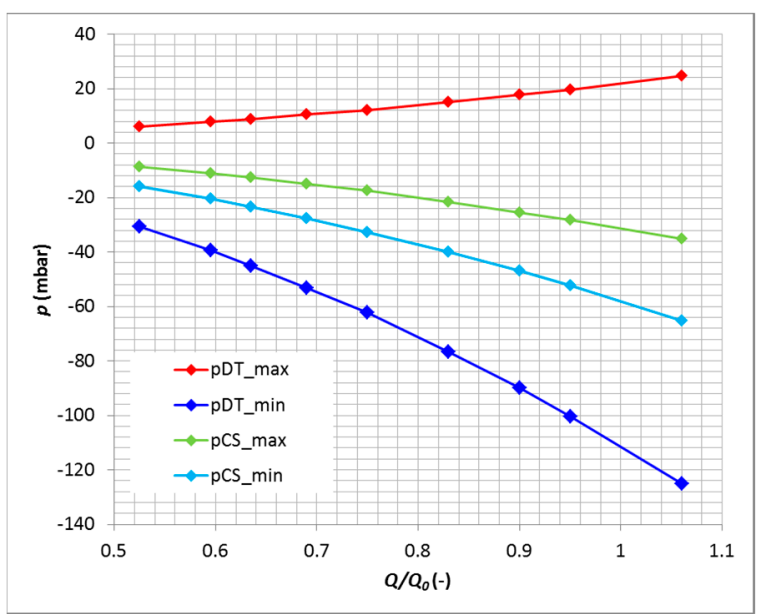

Figure 4. Minimum and maximum pressure simulated values in function of relative discharge in the draft tube (pDT_min, pDT_max) and cone section (pCS_min, pCS_max).

Additionally, analyzing the velocity vectors, it was observed that in this area (Figure 2a), the flow does not exhibit wall detachment. This suggests that no instabilities are present in the flow and thus no hydraulic sources can lead to vibrations. The streamlines in the proximity of the draft tube wall have a long trajectory between the launch point and the draft tube outlet (Figure $2 b$ ). This kind of trajectory is very favorable for the small bubbles because it avoids a concentration of bubbles in the central stagnant water zone and permits a long transfer (transit in flow) time for the oxygen from the bubble to the water.

The simulations performed for all the cases of discharge operation regimes revealed the minimum and the maximum pressure values in the entire draft tube (pDT_min, pDT_max) and in the cone section (pCS_min, pCS_max), as presented in Figure 4. The pressure level in the cone section was used to configure the size and distribution of the orifices [31] in order to obtain a minimum pressure loss when air passes through the aeration device, thus obtaining aeration with low energy consumption.

\subsection{Aeration System Design and Implementation}

The new aeration system (Figure 5) uses the natural aeration (NA) for the air admission in flow-if the pressure in the turbine draft tube cone is lower than atmospheric pressure - or the forced aeration (FA), supplied by compressed air-if the pressure in the turbine draft tube cone is higher or equal to atmospheric pressure. The air injection from the aeration device in the turbine hydraulic circuit is made through perforated plates that replicate the internal geometry of the turbine. The orifices have a diameter of $0.8 \mathrm{~mm}$ 
dispersed equidistantly with a step of five diameters to avoid the coalescence of the bubbles; this size is correlated with the void fraction admitted in the flow. The air injection is performed depending on the pressure level downstream runner and the dissolved oxygen DO deficiency in the water by actuating a control module [34]. The aim is to minimize the energy consumption required for aeration, choosing between natural aeration NA or forced aeration FA.

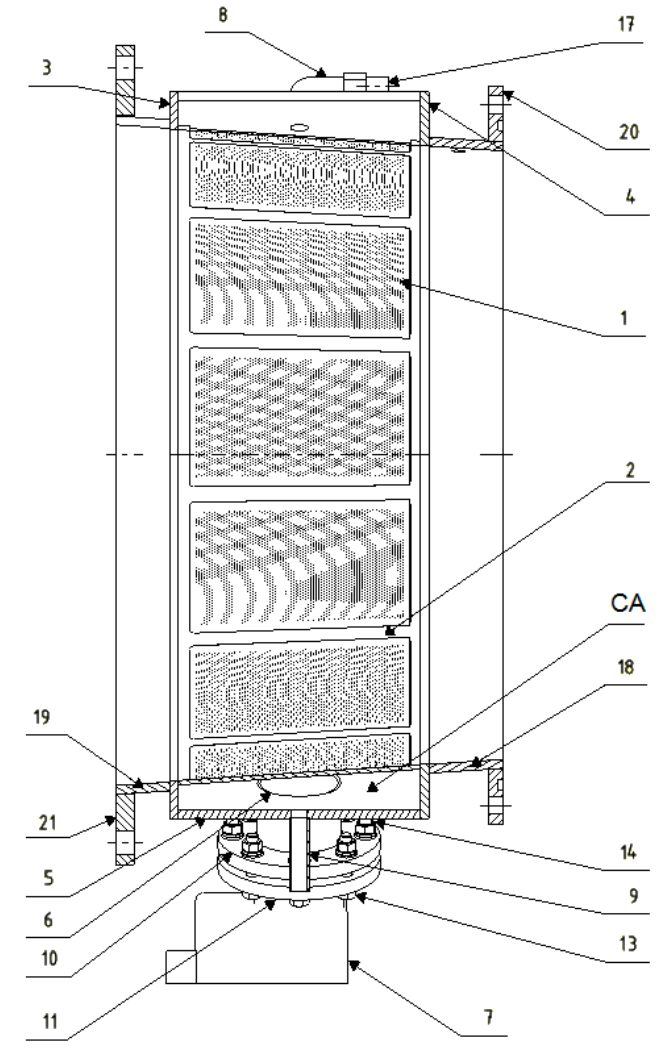

(a)

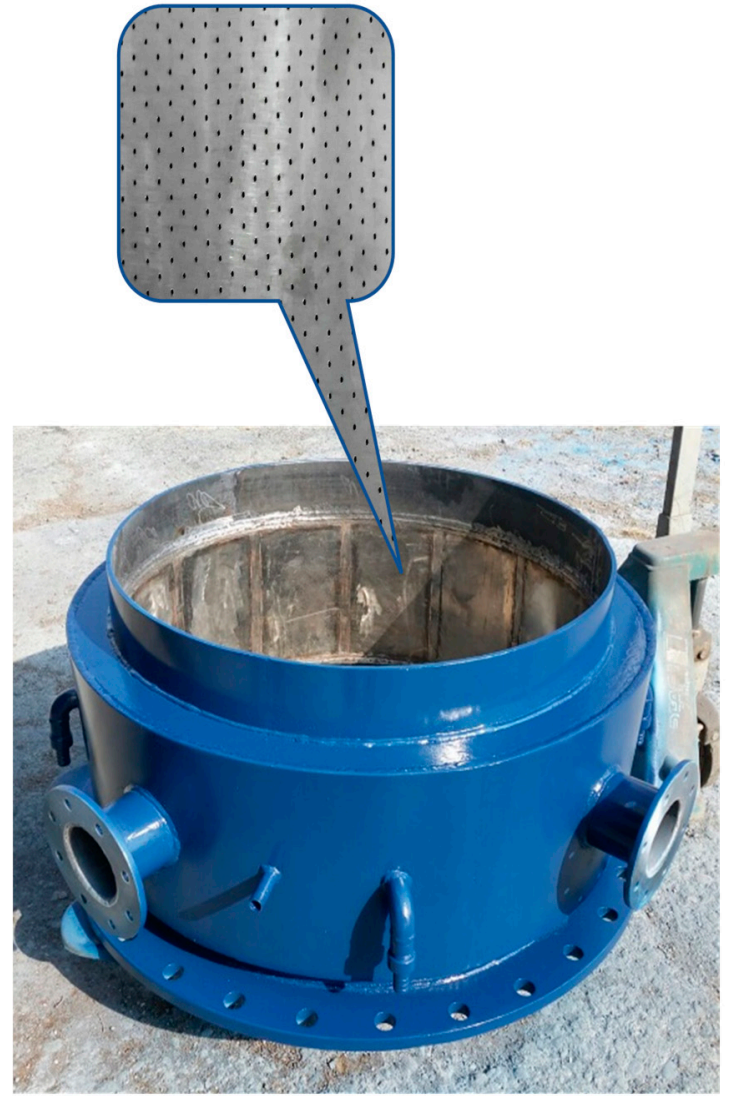

(b)

Figure 5. Water aeration system in hydraulic turbines, (a) section view, (b) photo of the aeration section (CA-air chamber, 1. perforated plates, 2. support grid, 3. upstream wall, 4. downstream wall, 5. an outer wall, 6. intake pipes, 7. valves, 8. air injection pipes, 9. drain plug, 10. flat flanges, 11. valve flange, 12. gasket, 13. hexagonal screws, 14. hexagon nut, 15. washer A, 16. grower $\mathrm{R}$ washer, 17. adapter, 18. upstream section, 19. downstream section, 20. upstream flange, 21. downstream flange).

This water aeration system for hydraulic turbines comprises a water aeration device that replicates exactly the flow passage of the draft tube cone of a hydraulic turbine and consists of an air chamber with the inner wall formed by perforated plates fixed on a support grid so that they completely or partially cover the inner wall-see Figure 5 . Thus, the flow in the draft tube is not disturbed by introducing singularities in the flow, and the hydraulic performance of the turbine is preserved after the installation of the aeration device. Depending on the operating regime of the turbine, the aeration is natural—without associated energy consumption or forced with compressed air. The air admission method and the use of fine bubbles minimize the impact on the flow structure, depending on the injected air flow rate (which is adjustable by valves and pneumatic system).

The aeration system operates considering two parameters: the relative pressure level in the draft tube cone and the downstream dissolved oxygen DO level. Thus, the hydraulic turbine water aerating device comprises a pressure tap and a transducer for measuring the pressure on the draft tube cone wall, upstream of the aeration device, as well as a dissolved 
oxygen DO sensor in the downstream section at the outlet of the turbine. The air admission is automatized, and the system is operated in natural or forced admission depending on the operating regime of the turbine. The system is active only when needed: low DO level and turbine are in operation, and air flow is limited at a maximum of 5\% of the water flow. In the case of startup, stop or runaway regime occurrence, the aeration device is shut down.

In Figure 6, the prototype of the aeration system for the hydraulic turbines and the bubble flow visualization inside the draft tube cone are presented. The visualizations were carried out using an optical boroscope with $90^{\circ} \times 8 \mathrm{~mm} \times 440 \mathrm{~mm}$ Hopkins lens, with integrated endoscopic video system TECHNO PACK ${ }^{\circledR}$ T LED from, Karl Storz Endoscopia Romania, Bucharest, Romania.

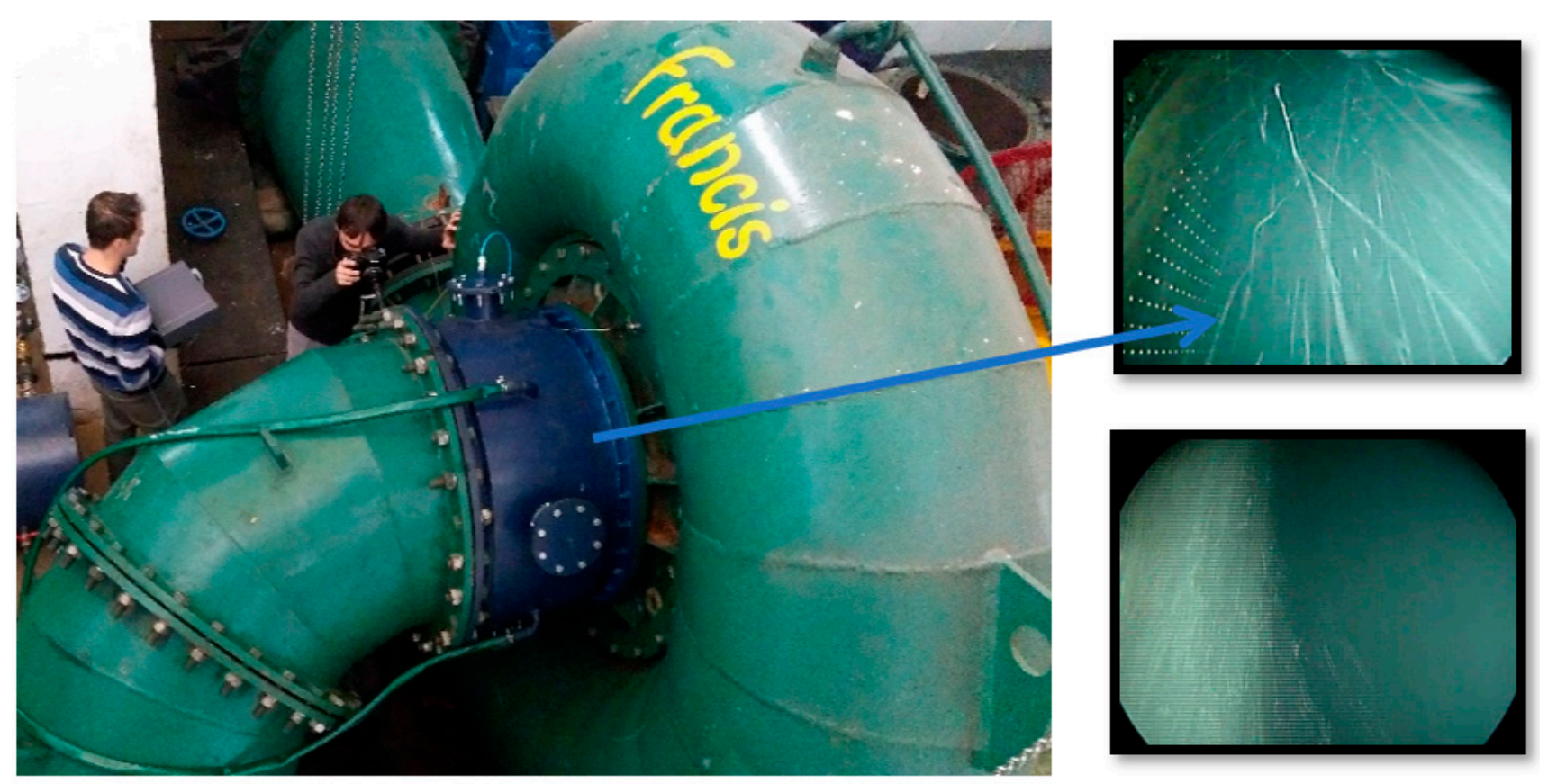

Figure 6. Implementation of the aeration prototype in hydraulic turbines and bubble flow visualization inside the draft tube cone.

These visualizations allowed optical validation of air injection in the flow section. Figure 6 shows individual (no coalescence) and centrifugal trajectory of the bubbles (the bubbles follow the flow and do not converge in the central dead water zone). In this way, the conditions for an optimized DO transfer are fulfilled: independent micro-bubbles to maximize the interfacial area of transfer and a long trajectory to increase the retention time of the bubbles in the flow.

The visualizations revealed the repartition of the bubbly flow inside the draft tube cone. The bubbly flow was centrifuged in the wall's proximity on a third of the cone radius. This bubble trajectory (a spiral along the draft tube walls) increases the transit time of the bubbles in the flow considerably, favoring a higher rate of the DO transfer. The visualization also presented no coalescence of the bubbles.

\section{Experimental Results}

\subsection{In Site Turbine Efficiency Study}

The efficiency measurements for the turbine without and with the aeration device in operation were carried out according to the standard from [35]. The following hydraulic and electrical parameters were measured: water levels upstream and downstream of the turbine, the pressure at the turbine inlet, the level at which the pressure transducer that measures the pressure at the turbine inlet is mounted, the flow rate, and the hydrogenerator power output. The uncertainty of the tests was evaluated to $1.5 \%$, following the standard from [35]. 
The air was introduced at the entrance of the draft tube elbow. A pressure sensor was located right below the aeration device in order to monitor the pressure in the water during the air injection at the runner outlet. The pressure transducer had an accuracy of $0.5 \%$.

In order to evaluate the energetic behavior of the turbine, based on the abovementioned measured parameters, the following quantities were determined:

- $\quad$ turbine net head, $H$

$$
H=\frac{p_{a m}}{\rho g}+\left(Z_{m, a m}-Z_{a v}\right)+\frac{v_{1}^{2}}{2 g}[\mathrm{~m}]
$$

- $\quad$ hydraulic power, $P_{h}$

$$
P_{h}=\rho g Q H,[W]
$$

- $\quad$ efficiency of the hydraulic turbine, $\eta_{T}$

$$
\eta_{T}=\frac{P_{G}}{\eta_{G} P_{h}}[-]
$$

where $Z_{m, a m}$ is the setting level of the pressure transducer measuring the turbine inlet pressure, $Z_{a v}$ - the measured downstream water level, $p_{a m}$ - the pressure measured at the inlet of the turbine, $v_{1}$ - the mean velocity at the inlet of the turbine, determined as the ratio between the measured flow rate and the pipe area $\left(v_{1}=Q / A\right), \rho$ - the water density, $g$ - the gravity, $Q$ - the measured turbine flow rate, $P_{G}$ - the measured electrical power output, and $\eta_{G}-$ generator efficiency.

The unit was operated over a power output range between $2 \%$ and $40 \%$ of the rated power, $P_{0}$, limited due to the on-site available conditions (i.e., water level in the upstream reservoir). The obtained turbine net head, $H$, was between $80 \%$ and $84 \%$ of the rated head value, $H_{0}$. Measurements were performed for several values of the turbine flow rate, $Q$, from $19 \%$ to $61 \%$ of the turbine rated flow rate, $Q_{0}$, corresponding to the guide vanes opening, s, from $30 \%$ to $100 \%$. For each turbine operating regime, air was injected with several flow rates, $Q_{a i r}$, between $1 \%$ and $8 \%$ of the turbine water flow rate (void fraction of $\phi=1-8 \%$ ).

A major concern was to analyze the impact of this aeration device by studying the air injection influence over the performances of the turbine. The pressure inside the draft tube cone section, $p_{C S}$, and the turbine efficiency during aeration, $\eta_{\phi}$, were determined for the above-mentioned operating regimes and compared with those measured during operating the turbine without air injection, $\eta_{T}$ (Figures 7 and 8, Table 2).

The variation of the turbine efficiency due to aeration was determined related to the value obtained when operating without air injection (Table 2)

$$
\Delta \eta=\frac{\eta_{\varphi}-\eta_{T}}{\eta_{T}} \cdot 100[\%]
$$

From the experimental results, it was found that the maximum turbine efficiency decreases of $2.8 \%$ occurred for a void fraction of about $5 \%$. It was observed that for the operation regimes with the void fraction below $5 \%$, the variation of the turbine efficiency was in the range of the efficiency measurement accuracy domain $( \pm 1.5 \%)$. The correlation between pressure evolution in the draft tube (Figure 7) and efficiency value (Figure 8) shows that unsuitable hydraulic phenomena (boundary layer detachment, increasing of the secondary flow at runner outlet) do not appear. For the lowest water flow rate, $0.19 Q_{0}$, and high void fractions ( $5 \%$ and $7 \%$ ), even an improvement of the energetic efficiency of the turbine was also observed, due to the increase in the pressure recovery (Figure 8). In conclusion, the air injection in the draft tube may be a possibility to improve both water aeration and the turbine efficiency at part load operation of reaction turbines [36]. 


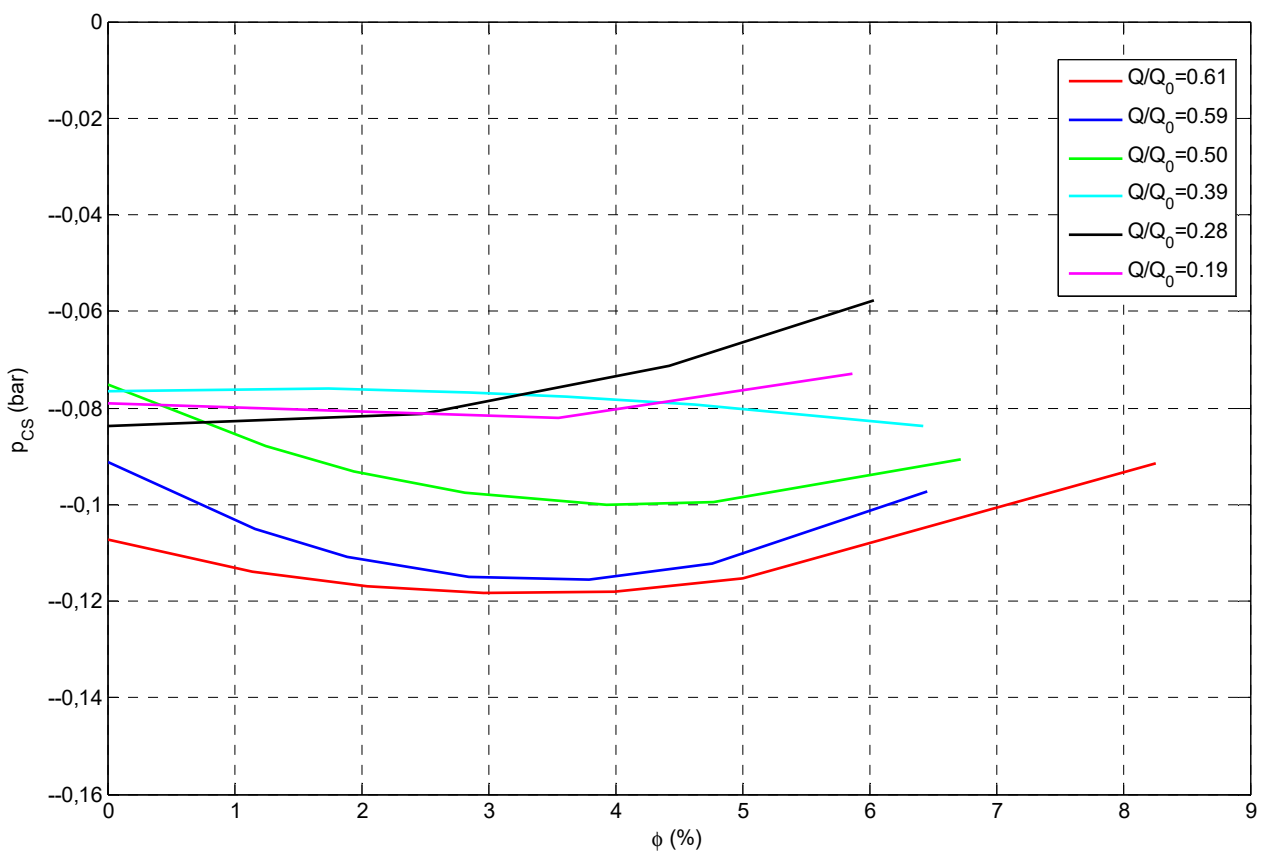

Figure 7. The pressure variation in the turbine draft tube cone section for the investigated operation regimes, with and without air injection.

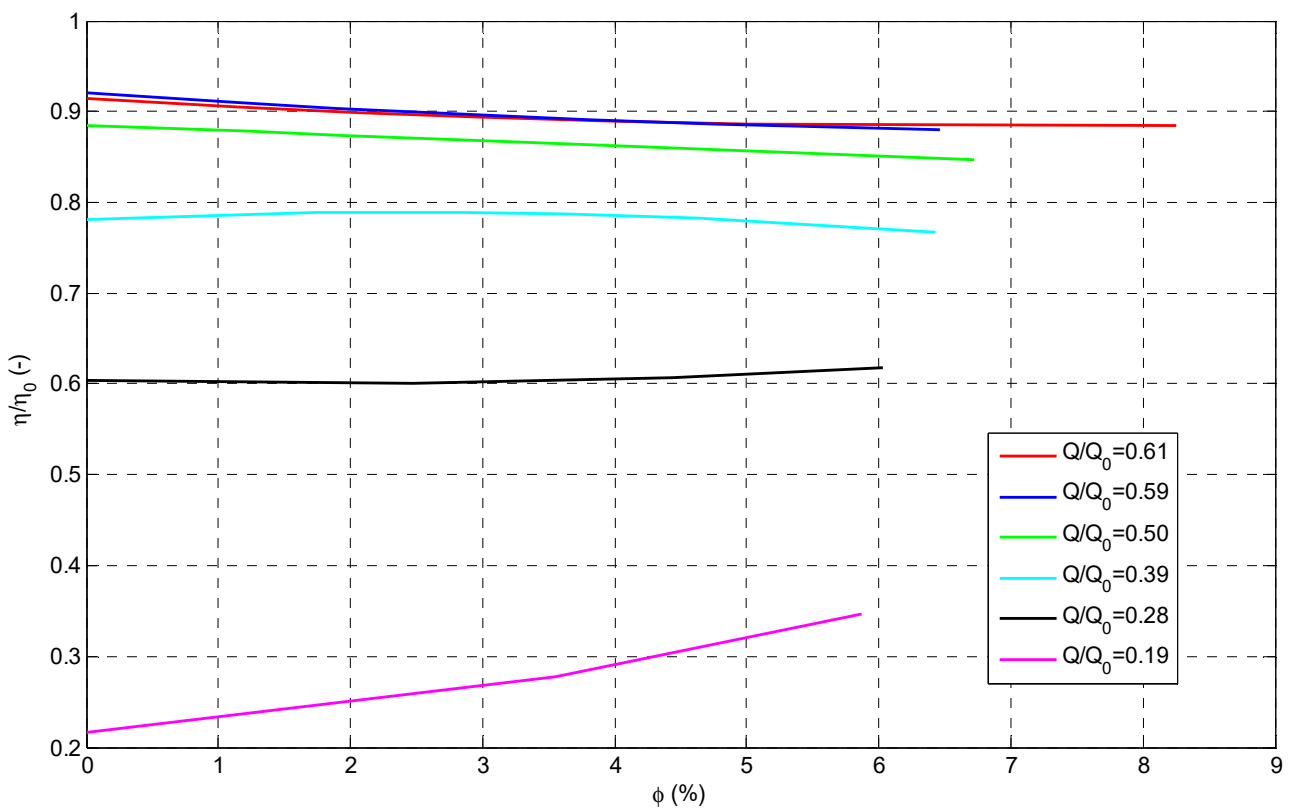

Figure 8. Variation of the turbine relative efficiency for the investigated operation regimes, with and without air injection.

Table 2. Variation of turbine efficiency $(\Delta \eta(\%))$ for the tested void fractions.

\begin{tabular}{ccccccccc}
\hline $\mathbf{H} / \mathbf{H}_{\mathbf{0}}$ & $\mathbf{Q} / \mathbf{Q}_{\mathbf{0}}$ & \multicolumn{7}{c}{$\boldsymbol{\phi ( \% )}$} \\
\hline $\mathbf{( - )}$ & $\mathbf{( - )}$ & $\mathbf{1}$ & $\mathbf{2}$ & $\mathbf{3}$ & $\mathbf{4}$ & $\mathbf{5}$ & $\mathbf{7}$ & $\mathbf{8}$ \\
\hline 0.80 & 0.61 & -0.5 & -1.3 & -1.7 & -2.1 & -2.0 & - & -2.5 \\
0.81 & 0.59 & -0.3 & -1.8 & -1.6 & -2.2 & -2.8 & -3.2 & - \\
0.82 & 0.50 & 1.1 & -0.6 & -0.9 & -1.5 & -1.7 & -2.5 & - \\
0.83 & 0.39 & -0.3 & 1.3 & 1.1 & -1.1 & -1.2 & - & - \\
0.84 & 0.28 & - & - & -0.03 & - & +0.2 & +1.3 & - \\
0.85 & 0.19 & - & - & - & - & +5.0 & +10.7 & - \\
\hline
\end{tabular}




\subsection{Mechanical Performances Study}

In the case of Francis turbines, the flow structure in the draft tube has a significant influence over their operation [37]. The vortex rope frequency (Figure 9) is transferred to the mechanical structure and can be observed as vibration frequency.

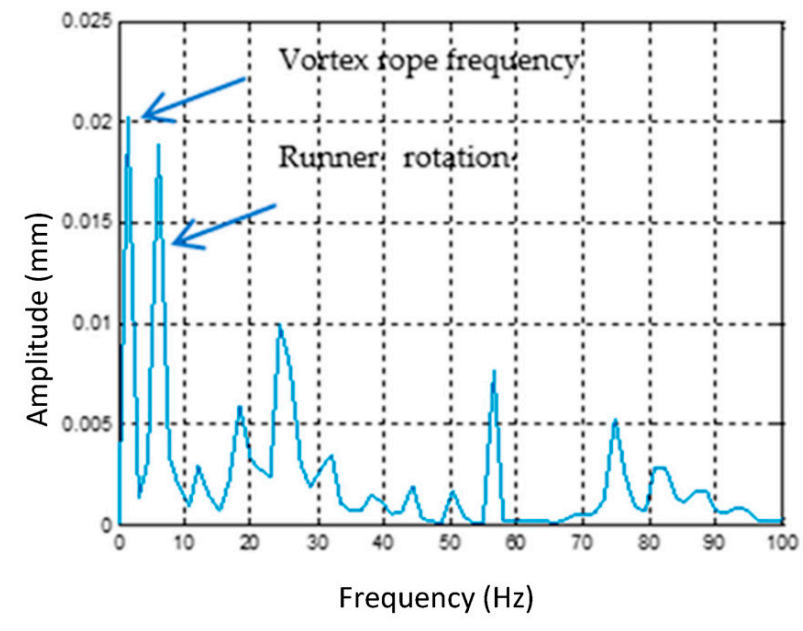

(a) $\phi=1.145 \%$

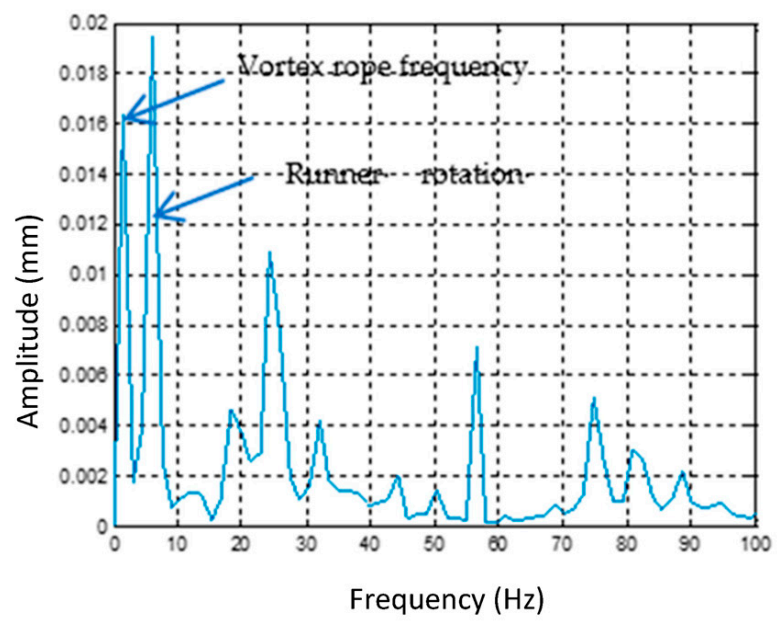

(b) $\phi=2.050 \%$

Figure 9. Amplitude spectrum of the vibrations obtained from displacement sensors on radial and axial direction located on the radial-axial bearing (a) for the $1.145 \%$ void fraction and (b) for the $2.05 \%$ void fraction.

In the spectral analysis of the vibrations obtained from displacement sensors on radial and axial direction, located on the radial-axial bearing, a reduced number of harmonics is observed. This suggests that the flow at the runner exit does not produce fluctuations able to interact with the mechanical structure. A component corresponding to the electrical grid frequency of $50 \mathrm{~Hz}$ is observed. Additionally, the component corresponding to the rotational speed of the unit of $6.25 \mathrm{~Hz}$ is present but with relatively low amplitudes.

Another major aspect for the validation of this aeration device in operation was related to the influence of the injected air over the mechanical behavior of the unit during operation. The vibrations were measured in the shaft bearings and in the casing of the unit. Four piezoelectric accelerometers, and two pairs of displacement probes are used. The location of the sensors and the detailed analysis of the results are detailed, presented in [38]. The frequency-domain analysis was carried out, having as its purpose to identify the main components in the amplitude spectra and to compare them in the case of no air injection to the ones when different air flow rates are injected.

Considering the influence of air injection in the hydraulic circuit of the turbine, there was no significant effect in addition to the observations from the energetic performance analysis of the unit (Figure 10).

The vibrations analysis indicated an intense dynamic behavior of the unit in operation for these operating regimes. Nevertheless, the air injection showed no significant influence over the amplitudes from the spectra of the vibration signals recorded on the radial-axial bearing and on the turbine housing. It was shown that the air injection using this new device into water, downstream of the runner, had no negative influence over the operation of the unit from a mechanical (structure) point of view. 


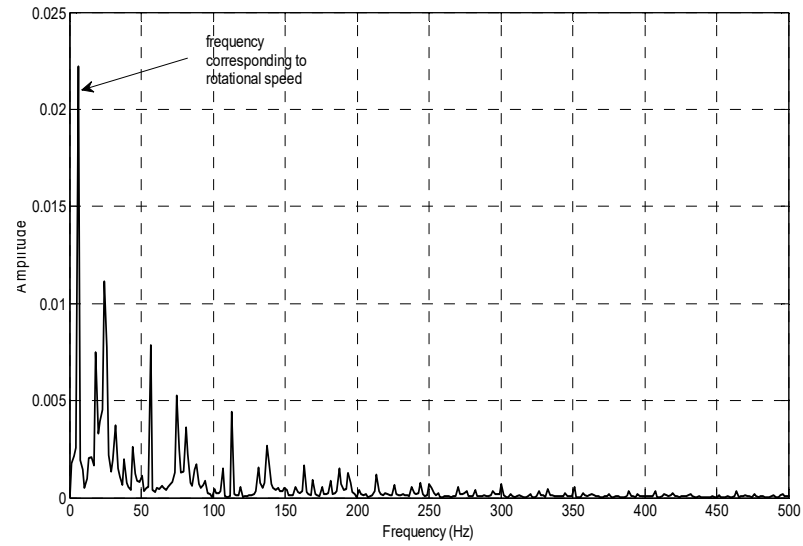

(a)

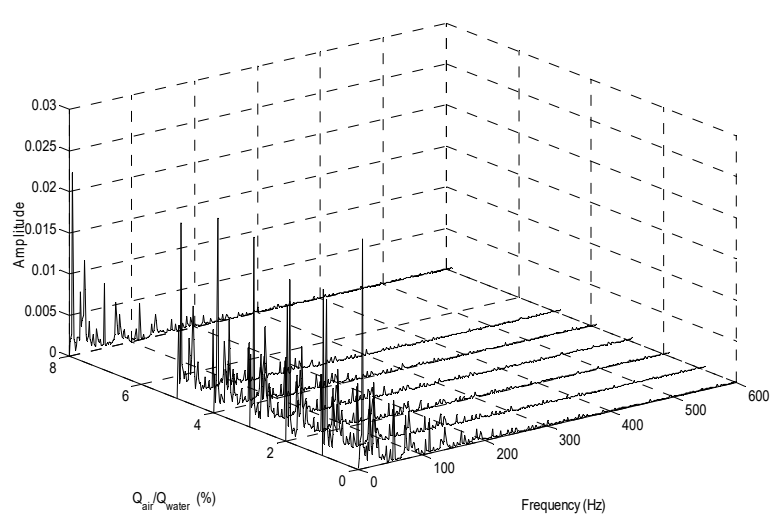

(b)

Figure 10. Amplitude spectrum of the vibrations obtained from displacement sensors on radial and axial direction, located on the radial-axial bearing, (a) for no air injection case and (b) for all operation regimes with different air flow rate injections [38].

\section{Conclusions}

The purpose of this research over the implementation of an innovative aeration device in a small Francis turbine was to establish the influence of the aeration process on the turbine's energetic and mechanical parameters.

First, a numerical study was conducted in order to determine the optimal position of the aeration device inside the hydraulic circuit of the turbine. The study indicated that the best position will be downstream of the turbine runner, at the entrance of the draft tube. Thus, in the cone section, perforated plates replicating the internal geometry of the draft tube were mounted. Their design was developed based on the previous studies of the authors over the aeration performances of different disperse aeration devices mounted non-invasively on the wall of a pipeline in a complex turbulent flow with a cavitational vortex. Further, the energetic and mechanical behaviors of the turbine, without and with the aeration device in operation, were determined experimentally.

From an energetic point of view, the tests showed that the impact of the aeration device implementation and operation on the energetic characteristics of the turbine did not exceed the efficiency measurements accuracy range. When the device was not in operation, its implementation had no effect on the turbine energetic performances. The experimental result analysis validated the developed aeration device, emphasizing that its influence on the hydraulic performances of the turbine is admissible economically.

The tested operating regimes were at partial load, near the operational limit of the turbine and the most unfavorable for the mechanical behavior, due to possible strong pressure fluctuations caused by the vortex rope. It was demonstrated that the aeration does not have a negative effect on the mechanical parameters of operation (vibrations, structural frequency excitation, or misalignments).

The successful implementation of this aeration system has proven the technical feasibility of the prototype. The use of the aeration system did not significantly affect the energetic performances of the turbine, and its implementation could be considered from an economic point of view. The aeration with fine bubbles is the most efficient aeration method from the DO transfer, and the location of the system in the turbine is not only favorable for the aeration process (bubbles transit time and mixing of the air flow) but also very accessible for implementation and maintenance.

The implementation impact of this innovative aeration device on turbine performance was fully assessed and shows the technical and economic viability of its use in the industrial operation of hydraulic turbines. 
This innovative aeration system is fully characterized from an energetic point of view: air consumption for aeration as well as the influence on the turbine efficiency. The system can be implemented on any turbine where the level of the dissolved oxygen is lower compared with the ecological one [1] in maintenance or refurbishment activity.

\section{Patents}

The following patent resulted from the work reported in this paper. Bunea F., Ciocan G.D., Nedelcu A, Bucur D.M., Dunca G., Codescu S., Water aeration system for the hydraulic turbines, Eurasian Patent no. 036765/17.12.2020 B1.

Author Contributions: Conceptualization, F.B., G.D.C. and D.M.B.; Methodology, F.B., G.D.C., D.M.B. and G.D.; Formal Analysis, A.N.; Investigation, F.B., D.M.B., G.D. and A.N.; Writing-Original Draft Preparation F.B.; Writing-Review and Editing, D.M.B. and G.D.; Supervision, G.D.C.; Project Administration, F.B. All authors have read and agreed to the published version of the manuscript.

Funding: This research was funded by UEFISCDI Romania, grant numbers PN-III-P2-2.1-PED-2019-3247, PNII 88/2014 and POC 126/D4/2020.

Institutional Review Board Statement: Not applicable.

Informed Consent Statement: Not applicable.

Data Availability Statement: No new data were created or analyzed in this study. Data sharing is not applicable to this article.

Acknowledgments: This work was supported by a grant of the Romanian Ministry of Education and Research, CCCDI-UEFISCDI, project number PN-III-P2-2.1-PED-2019-3247, within PNCDI III, and by the projects ECOTURB PNII 88/2014 and POC 126/D4/2020.

Conflicts of Interest: The authors declare no conflict of interest.

\section{References}

1. Water Framework Directive. Common Implementation Strategy for the Water Framework Directive (2000/60/EC). Guidance Document No. 7, Monitoring under the Water Framework Directive (2003). Available online: http://www.wrrl-info.de/docs/ wetlands\%20030801\%20horizonal\%20guidance.pdf (accessed on 9 March 2021).

2. Bunea, F.; Maria, D.; Elena, G.; Dan, G. Water Quality in Hydroelectric Sites. Ecol. Water Qual. Water Treat. Reuse 2012, 1, $391-408$.

3. Ponsonnet, H.; Ibrahim, A.; Resler, D.; Sims, R.; Li, P.; Castillo, C.; Tsui, K.N.; Starks, M. Economic Viability of Dissolved Oxygen Amelioration in Tailwater of Hydroelectric Dams to Ensure Wildlife Indemnity. CEE 361: Environmental Engineering. 2015. Available online: https:/ /www.academia.edu/20366536/Actual_Report (accessed on 10 November 2019).

4. Wool, T.; Ambrose, R.B., Jr.; Martin, J.L.; Comer, A. WASP 8: The Next Generation in the 50-Year Evolution of USEPA's Water Quality Model. Water 2020, 12, 1398. [CrossRef] [PubMed]

5. Ling, T.; Nyanti, L.; Theresa, M.; Jongkar, G.; Sim, S.; Aazani, M. Physico-chemical Characteristics in the Filling Phase of Bakun Hydroelectric Reservoir, Sarawak, Malaysia. Int. J. Applied Sci. Technol. 2012, 2, 6.

6. Rakhmatullaev, S.; Huneau, F.; Le Coustumer, P.; Motelica-Heino, M.; Bakiev, M. Facts and Perspectives of Water Reservoirs in Central Asia: A Special Focus on Uzbekistan. Water 2010, 2, 307-320. [CrossRef]

7. Tomczyk, P.; Wiatkowski, M. Shaping changes in the ecological status of watercourses within barrages with hydropower schemes-Literature review. Arch. Environ. Prot. 2020, 46, 78-94. [CrossRef]

8. Bunea, F.; Bucur, D.M.; Ciocan, G.D.; Dunca, G. Aeration solution of water used by hydraulic turbines to respect the environmental policies. In Proceedings of the 2014 International Conference and Exposition on Electrical and Power Engineering (EPE), Iasi, Romania, 16-18 October 2014; pp. 1015-1020. [CrossRef]

9. Zhang, Y.; Wu, Z.; Liu, M.; He, J.; Shi, K.; Zhou, Y.; Wang, M.; Liu, X. Dissolved oxygen stratification and response to thermal structure and long-term climate change in a large and deep subtropical reservoir (Lake Qiandaohu, China). Water Res. 2015, 75, 249-258. [CrossRef] [PubMed]

10. Zhou, Z.-Z.; Huang, T.-L.; Ma, W.-X.; Li, Y.; Zeng, K. Impacts of water quality variation and rainfall runoff on Jinpen Reservoir, in Northwest China. Water Sci. Eng. 2015, 8, 301-308. [CrossRef]

11. Ling, T.C.; Phang, K.S.; Soo, C.L.; Nyanti, L.; Sim, S.F.; Grinang, J. Spatiotemporal profiles of water quality at a new large tropical hydroelectric dam reservoir. AACL Bioflux 2019, 12, 893-907.

12. Liu, W.-C.; Liu, S.-Y.; Hsu, M.-H.; Kuo, A.Y. Water quality modeling to determine minimum instream flow for fish survival in tidal rivers. J. Environ. Manag. 2005, 76, 293-308. [CrossRef] [PubMed]

13. Zhang, L.-X.; Chen, L.-Y.; Peng, X.-X.; Shao, X.-M. The effect of water quality on tip vortex cavitation inception. J. Hydrodyn. 2017, 29, 954-961. [CrossRef] 
14. Harshbarger, E.D.; Herrold, B.; Robbing, G.; Carter, J.C. Turbine Venting for Dissolved Oxygen Improvements at Bull Shoals, Norfork, and Table Rock Dams. In Proceedings of the Waterpower '99; American Society of Civil Engineers (ASCE), Las Vegas, NV, USA, 6-9 July 1999.

15. March, P.A.; Brice, T.A.; Mobley, M.H.; Cybularz, J.M. Turbines for Solving the DO Dilemma. Hydro-Rev. 1992, $11,30-36$.

16. March, P.A.; Jacobson, P. Industry Experience with Aerating Turbines. In Proceedings of the HydroVision 2015; PennWell Corporation: Tulsa, OK, USA, 18 July 2015. Available online: https://www.researchgate.net/publication/314855911_Industry_ Experience_with_Aerating_Turbines (accessed on 15 March 2018).

17. March, P.A.; Waldrop, W.R. Technology Development for Auto-Venting Turbines. In Proceedings of the 2nd International Symposium on Gas Transfer at Water Surfaces ASCE, Minneapolis, MN, USA, 1991; pp. 506-515.

18. Papillon, B.; Sabourin, M.; Couston, M.; Deschenes, C. Methods for air admission in hydroturbines. In Proceedings of the XXIst IAHR Symposium on Hydraulic Machinery and Systems, Lausanne, Switzerland, 9-12 September 2002.

19. Rohland, K.; Foust, J.; Lewis, G.; Sigmon, J. Aeration Turbines for Duke Energy's New Bridgewater Powerhouse. Hydro-Rev. 2010, $29,58-63$.

20. Sullivan, A.; Bennet, K. Retrofit Aeration System (RAS) for Francis Turbine. Final Report; Contract FC36-02ID14408; Ameren UE and MEC Water Resources Inc: Saint Louis, MO, USA, 2006. [CrossRef]

21. Perkinsin, A.; Dixon, D.; Dham, R.; Fous, J. Development Status of the Alden Fish-Friendly Turbine. Hydro-Rev. 2013, 32, 46-55.

22. Quaranta, E. The Revival of Old Hydraulic Turbines for Innovative Hydropower Generation: Water Wheels, Archimedes Screws, Deriaz and Girard Turbines. Curr. Trends Civ. Struct. Eng. 2020, 5, 1-4. [CrossRef]

23. Buscaglia, G.C.; Bombardelli, F.A.; García, M.H. Numerical modeling of large-scale bubble plumes accounting for mass transfer effects. Int. J. Multiph. Flow 2002, 28, 1763-1785. [CrossRef]

24. Daskiran, C.; Riglin, J.; Schleicher, W.C.; Oztekin, A. Computational study of aeration for wastewater treatment via ventilated pump-turbine. Int. J. Heat Fluid Flow 2018, 69, 43-54. [CrossRef]

25. Vahaji, S.; Han, J.; Cheung, S.C.; Yeoh, G.; Tu, J. Numerical investigation on the bubble size distribution around NACA0015 hydrofoil. Ocean Eng. 2019, 172, 59-71. [CrossRef]

26. Karn, A.; Monson, G.M.; Ellis, C.R.; Hong, J.; Arndt, R.E.; Gulliver, J. Mass transfer studies across ventilated hydrofoils: A step towards hydroturbine aeration. Int. J. Heat Mass Transf. 2015, 87, 512-520. [CrossRef]

27. Choi, B.-B.; Choi, Y.-J.; Choi, J.-S.; Lee, S.; Oh, H.-J. Energy management in submerged microfiltration systems by optimum control of aeration. Desalination 2009, 247, 233-238. [CrossRef]

28. Leu, S.-Y.; Rosso, D.; Larson, L.E.; Stenstrom, M. Real-Time Aeration Efficiency Monitoring in the Activated Sludge Process and Methods to Reduce Energy Consumption and Operating Costs. Water Environ. Res. 2009, 81, 2471-2481. [CrossRef]

29. Bunea, F.; Ciocan, G.D. Experimental Study of Standard Aeration Efficiency in a Bubble Column. Desalination Water Treat. 2018, 54, 224-235. [CrossRef]

30. Murgan, I.; Bunea, F.; Ciocan, G.D. Experimental PIV and LIF characterization of a bubble column flow. Flow Meas. Instrum. 2017, 54, 224-235. [CrossRef]

31. Bunea, F.; Nedelcu, A.; Ciocan, D.G. Prediction of water aeration efficiency in high turbulent flow. Desalination Water Treat. 2017, 85, 55-62. [CrossRef]

32. Krivchenko, G.I. Hydraulic Machines: Turbines and Pumps; Lewis Publishers: Boca Raton, FL, USA, 1994; ISBN 13: 978-1566700016.

33. Tridon, S.; Barre, S.; Ciocan, G.D.; Tomas, L. Experimental analysis of the swirling flow in a Francis turbine draft tube: Focus on radial velocity component determination. Eur. J. Mech.-B/Fluids 2010, 29, 321-335. [CrossRef]

34. Bunea, F.; Ciocan, G.D.; Nedelcu, A.; Bucur, D.M.; Dunca, G.; Codescu, S. Water Aeration System for the Hydraulic Turbines. Eurasian Patent No 036765, 17 December 2020.

35. IEC 60041:1991. International Standard-Field Acceptance Tests to Determinate the Hydraulic Performance of Hydraulic Turbines, Storage Pumps and Pump-Turbines, Geneve, 1991. Available online: https:/ / webstore.iec.ch/publication/154 (accessed on 7 September 2021).

36. Kougias, I.; Aggidis, G.; Avellan, F.; Deniz, S.; Lundin, U.; Moro, A.; Muntean, S.; Novara, D.; Pérez-Díaz, J.I.; Quaranta, E.; et al. Analysis of emerging technologies in the hydropower sector. Renew. Sustain. Energy Rev. 2019, 113, 021105. [CrossRef]

37. Iliescu, M.S.; Ciocan, G.D.; Avellan, F. Analysis of the Cavitating Draft Tube Vortex in a Francis Turbine Using Particle Image Velocimetry Measurements in Two-Phase Flow. J. Fluids Eng. 2008, 130, 021105. [CrossRef]

38. Bucur, D.M.; Dunca, G.; Bunea, F.; Calinoiu, C. Aeration process influence over the operation of a small hydro turbine-Generator unit. In Proceedings of the 2017 10th International Symposium on Advanced Topics in Electrical Engineering (ATEE), Bucharest, Romania, 23-25 March 2017; pp. 746-751. 